\title{
Learning by arguing about evidence and explanations
}

\author{
J. Dowell \\ Computer Science, University College London, London WC1E 6BT, UK. \\ j.dowell@cs.ucl.ac.uk
}

\author{
M. Asgari-Targhi \\ ESRC National Centre for e-Social Science (NCeSS), University of Manchester, \\ Manchester M13 9PL, UK.
}

Argumentation is a defining feature of collaborative learning. We investigated collaborative case-based learning in order to identify the argumentation scheme which learners use in constructing shared explanations over evidence. We observed medical students attempting to explain how a judge had arrived at his verdict in a case of medical negligence. The students were learning within a virtual learning environment and their communication was computer mediated. We examine the dialogue between these learners and discover the abductive argumentation scheme which characterises it. We also assessed the students' learning and propose that it is related to particular features of the abductive argumentation scheme.

\section{Argumentation and case-based collaborative learning}

Cases are natural objects for collaborative learning, stimulating spontaneous discussion and inquiry. A case presents a set of facts bound together within a scenario or narrative containing an issue; this issue gives rise to the need for explanation or resolution. In this paper, we make use of a legal case of medical negligence where the issue was to explain why the judge had arrived at his verdict. Case-based collaborative learning of this kind has become an established part of vocational and professional training, most visibly in law, management and medicine. It is also a promising opportunity for the application of learning technologies. However designers of learning environments for case-based learning will need to know how learners learn through discourse. Design of the resources, tasks, functionalities and representations of learning environments all need to be grounded in a cognitive level account of the reasoning and related learning processes which characterize case-based learning. For example, whether learners consider and compare alternative explanations for a set of evidence is a question which has significant implications for designing learning environments for case based collaborative learning. The work we report here is a contribution towards answering the question of how learners reason and learn in collaborative case based learning settings.

Argumentation is an analytical prism through which to view collaborative learning with cases and specifically, the reasons and reasoning embodied in dialogue. It applies to situations in which reasoning can lead to different conclusions, but it is not limited to adversarial dialogues or disagreements. For example, argumentation occurs when people collaborate on some inquiry where they together explore different explanations for some issue.

Argumentation then, concerns primarily the content of discourse, as well as its rhetorical forms. The work we report examines the argumentation in a collaborative case-based learning setting.

Research into argumentation and learning aims to understand "how argumentation produces learning, that is, to discover which cognitive mechanisms, triggered by argumentative 
interactions, generate new knowledge and in which conditions" (Jermann and Dillenbourg, 2003). Baker has proposed that there may be three general mechanisms through which argumentation produces learning (Baker, 2003). First articulating solutions may produce knowledge restructuring in a manner equivalent to the self-explanation effect. The discourse encourages the elaboration and coherence of arguments which has the effect of testing and developing knowledge. The second way is due to the dialectical dimension of the argumentation, where the status of arguments is challenged and new beliefs are acquired as the result of successful refutations and defenses. Recognising the subtle epistemic shades of a proposition will also occur and is part of the development of knowledge. The third way is the negotiation of meaning, conceptual dissociation and knowledge elaboration as integral parts of the argumentation process. These three suggestions usefully illustrate what the cognitive mechanisms referred to by Jermann and Dillenbourg may look like and the need to explicitly capture a relationship between knowledge, learning and argument.

Our concern is with collaborative case-based learning and the cognitive mechanism through which new knowledge is triggered by argumentation. It is likely that case based learning involves a characteristic argumentation scheme to which learning will be systematically related. To examine this conjecture we studied a group of medical students engaged in case based learning in a virtual learning environment. The students were developing their understanding of the law of medical negligence through analyzing a documented case in which a General Practitioner (GP) was accused of causing a patient to suffer a stroke. Our study sought to examine first, whether an argumentation scheme could be detected in the students' dialogue and second, whether learning could be interpreted from the students' dialogue and associated with the argumentation scheme.

The approach we adopted to investigating argumentation involved an interpretive knowledge analysis of dialogues at the level of individual contributions. This approach has been established in earlier work on collaborative learning, for example by Roschelle who examined how two students develop a shared understanding of mechanics through working together with an interactive simulation of a simple mechanics problem. By examining the use of terms and conceptual relationships in individual contributions to the dialogue, individually held concepts of 'lengthening' and 'pulling' are seen to become integrated into the single concept of 'travel along' (Roschelle, 1992). In our investigation we adopt a similar interpretive method for knowledge analysis of dialogue transcripts.

We first describe the online learning setting we established within our virtual learning environment and present data we collected. This includes a complete account of the materials used in the study which are essential to understanding the dialogue which the students construct between themselves. We then examine the dialogue and classify it against the typology of dialogues provided by critical argumentation theorists. We then isolate and identify the characteristic form of argumentation scheme in the dialogue, a form which we refer to as an abductive argumentation scheme. Finally we attempt to identify whether learning outcomes are consistently associated with the argumentation scheme.

\section{Observation of collaborative case-based learning in a distributed environment}

We developed a case-based learning activity in medical law for undergraduate students taking a taught module on professional issues for clinicians. The setting for this learning activity was a virtual collaborative learning environment (Sirrochi, 2003). The students had already attended a lecture on the law of medical negligence and the learning experience we designed for our study substituted for the planned class work which would have involved a similar face-to-face discussion of cases. Our learning experience was focused on a case in which a 
general practitioner had been accused of negligence that it was claimed resulted in a patient suffering a stroke. This case was adapted for the purposes of our study from the account given by Goldberg and targeted the key concepts of negligence: (i) a breach of a duty of care, and (ii) actual harm caused by a breach of duty of care (Goldberg, 2000). For present purposes we can regard these concepts as equivalent to the lay-concepts of 'being at fault' and 'being to blame (for what happened)'. The relationship between these elements is potentially complex, and different qualities and forms of causation are possible. It is possible, for example, to find that the GP had breached their duty of care and had been negligent in a restricted sense, but that the GP was not liable for harm suffered by a patient because their negligence could not be said to have caused the harm.

A single group of three undergraduate medical students participated in this case based learning experience. The students were initially given ten minutes to write individual accounts of their understanding of the law of medical negligence, including illustrative examples of negligence that came to mind. This task was performed online in a separate editor window. The students were then introduced to the virtual learning environment which included a chat messaging system for communication, a hypertext case library, a shared whiteboard, and a display area for presenting the task briefing. Next the students were given five minutes to read a short summary (reproduced in Figure 1) of the lecture on medical negligence they had attended. The students were then presented with the description of the 'Vadera vs Shaw' case (Figure 2) and were asked to explain the judge's verdict of 'negligent but not liable’.

The students were given ten minutes to read the details of the case, they then began their discussion. The case details and the lecture resume were available throughout the discussion. The record of their dialogue is reproduced in Figure 3 and includes the timestamp of each contribution. The order of a small number of contributions (those where the \{timestamp is enclosed in brackets) has been changed to make clearer the intended sequence of exchanges, a sequence which is typically disrupted by the time-ordered, post-once nature of chat systems. After completing their discussion of the case the students were then asked to write brief individual accounts of what they believed to be the important issues in the case.

Given the aim of relating learning to argumentation, we needed to assess what the students may have learnt through their discussion of the Vadera case. We therefore adopted the approach used by Suthers and Hundhausen in their analysis of dialogues collected in problem based collaborative learning sessions (Suthers and Hundhausen, 2003). We produced a domain analysis of the Vadera and Shaw case (see Figure 4) in which the case was interpreted against the key elements of the law of medical negligence as given in the lecture summary. Hence the domain analysis consists of identifying the hypotheses which could be developed from the case, the relevant case facts supporting each hypothesis, and the explanation which related the facts to the hypothesis. The analysis consists of six hypotheses, each with a corresponding explanation, and nine facts in total. The same facts can be associated with two competing hypotheses because the explanations given with each of those hypotheses allow different interpretations of those facts.

The hypotheses H2, H3, and $\mathrm{H} 4$ are alternative hypotheses, and hypotheses $\mathrm{H} 5$ and $\mathrm{H} 6$ are alternative hypotheses; hypotheses $\mathrm{H} 5$ and $\mathrm{H} 6$ are dependent on accepting hypothesis 4 and rejecting hypotheses $\mathrm{H} 2$ and $\mathrm{H} 3$. The original verdict of negligent but not liable is therefore explained by H1, H4 and H5. In our analysis the facts have only consistent relationships with the hypotheses, unlike Suther's analysis which additionally allowed inconsistent relationships. Using this domain analysis as describing an idealized learning outcome, we 
coded the students' dialogue for explicit reference to each of the hypotheses. We coded references to the hypotheses as they occurred in the dialogue, explicit reference to the set of facts contained in the domain model, and articulation of the explanations.

\section{Argumentation type and schema}

We are interested in the reasoning of our students as they sought to explain the judge's verdict. We are examining that reasoning through the analytic prism provided by argumentation which allows us to examine the form and content of shared reasoning. Argumentation offers a typology of dialogues in relation to the purposes of the discourse, the knowledge which the participants possess initially and their initial positions, and the methods used in the discourse. Types of dialogue include debate, persuasion, inquiry and negotiation dialogues (Walton, 1989). At a lower grain of analysis, argumentation is concerned with the form of arguments within distinct episodes within a discourse. Here we first describe the type of argument which our students exhibited during the learning experience. This account examines the structure of the argumentation at a high level. We then identify the argumentation scheme which characterizes the form of reasoning which the students exhibited.

\subsection{The dialogue type}

By viewing argumentation as a kind of informal logic, we can see how reasoning advances by inferring one proposition on the basis of other propositions. This reasoning is usually within a dialectical discourse where alternative interpretations and conclusions are proposed by different participants in the dialogue. Argumentation leads the parties in a dialogue to make commitments to particular propositions and their store of commitments accumulates through the dialogue. In the dialogue the students approach the task of explaining the original verdict in the case by discussing what verdict they themselves would have given. The students take different points of view on this question at the outset and the ensuing discussion is a series of exchanges through which they arrive at a consensus conclusion. The argumentation can be identified with two types of dialogue, persuasion dialogues and inquiry dialogues.

There are distinct features of persuasion in the argumentation as Gemma and Hywel persuade David to change his mind and agree that the GP was negligent. Persuasion arguments arise in the competition between two hypotheses and have a characteristic method which is to prove a thesis from premises that the other party concedes. David for example concedes the premise proposed by Gemma that the GP should have taken further blood pressure readings; David then finds himself forced to agree with Gemma's assertion that the GP was negligent. The persuasion argument is asymmetric in this case, because whilst Gemma and Hywel believe strongly that the GP was negligent, David does not strongly believe that the GP was not negligent; he holds the more neutral view that the GP was merely naïve. David is not attempting to negate Gemma's argument but only to resist and question it and so the hypotheses in this argumentation are weakly opposed.

As the dialogue advances, concessions made by David are used by Gemma and Hywel to support their claim that the GP was negligent. Further case facts are introduced by the students as the dialogue proceeds and interpreted to support their arguments. For example, in Episode 4 Gemma introduces the important fact that it is unknown whether the GP took a patient history; by implication the GP did not and therefore ignored a potential source of confirmation of the blood pressure reading or of the hypertension diagnosis. David concedes this fact which now becomes an additional premise for Gemma's conclusion that the GP was negligent (Hypothesis H4) which David is then forced to tacitly concede. 
As the dialogue progresses each participant maintains a set of commitments which can be seen as a set of distinct propositions to which additions or deletions are made. The set of propositions to which each person is making a commitment is visible to the other participants in the argument. These propositions are the semantic core of the argument made up of one or more conclusions and a set of premises.

As well as these features of persuasion, the argumentation also exhibits the distinctive features of an inquiry. Inquiry arguments have the character of accumulating increments of knowledge (Walton, 1989) and typically begin by acknowledging an initial lack of essential knowledge; evidence is given the highest priority in inquiry arguments. The three students are clearly immersed in such an inquiry as they sift the facts about the GP's actions and judgements and the patient's state.

This sifting is an uneven process where the students struggle to assess the relevance and significance of the given facts of the case, and to make inferences about the likelihood of other implicit facts. The disputed follow-on consultation is a fact which causes the students particular difficulty. David goes so far as to suggest in Episode 5 that it was the crux of the case and that only if the GP ignored the adverse effects of the prescription would they be negligent. The argumentation is enthymematic because it implicitly (but incorrectly) assumes that the act of making the prescription in the first place could not have been negligent. It is also indicative of the student's inexperience in dealing with such legal problems that they are willing to dwell on the disputed consultation rather than concentrating on the incontrovertible facts.

The facts of the case must be interpreted as premises for the conclusion they are arguing for, and the students struggle to recognise the important premises into which the facts can be fitted. A decisive argument is made by Gemma in Episode 6 when she proposes that the GP's liability turns on whether the patient would have suffered the stroke if she hadn't been given the prescription. The decisiveness of this counter-factual argument is accepted and the given statistical evidence about the link between the pill and strokes is then easily fitted into the developing argument, producing the conclusion that the GP could not be shown to be liable.

Participants in inquiry arguments adopt a characteristically neutral attitude towards the possible hypotheses and their dialogue is cooperative rather than adversarial (Walton, 1989). The three students' clearly do not adopt neutral attitudes towards the alternative hypotheses, owing to the components of persuasion it contains as already discussed. However the dialogue is highly cooperative.

In sum we are able to identify the essential argumentation elements of the student's dialogue in relation to its purpose and technique. We are also able to associate the argumentation with Walton's typology. We now go further into the argumentation analysis to identify the characteristic argumentation scheme which the students deploy.

\subsection{The argumentation scheme}

Argumentation schemes are stereotypical inferential structures of arguments within discourse. Recurring forms of argument were first identified in the form of fallacies, such as the ad hominem fallacy in which an argument attacks the person rather than what they are saying. Another example is the 'slippery slope' argument where conceding one proposition inevitably leads to conceding others and accepting an unacceptable conclusion. Whereas these ancient ideas of argument structure were limited to reasoning which was faulty in some 
way, Walton has shown that argumentation schemes can be found in discourse more generally, and one which is particularly significant is the abductive scheme.

The abductive argumentation scheme describes the synthetical hypothesis about causes. It applies to situations where an explanation needs to be formed and where different explanations are possible; abduction is sometimes referred to as 'inference to the best explanation' (Honderich, 1995). Josephson and Josephson (1996) argue that much reasoning in ordinary life, in science, in medicine and in law is abductive; they express agreement with Charniak's view that the two primary functions of cognition are abduction and planning. Magnani (1992), citing Simon $(1965,1977)$ also comments "I completely agree with Simon: abduction is the main subject of problem solving, and developments in the fields of cognitive science and artificial intelligence have strengthened this conviction”.

Abductive reasoning is intrinsically creative, forming partial knowledge into more complete and general knowledge. Pierce, the logician philosopher credited with identifying abductive reasoning said of abductive inference that it "comes to us like a flash... it is the idea of putting together what we had never before dreamed of putting together which flashes the new suggestion before our contemplations" (Pierce 1997). Abduction therefore holds considerable promise as an account of how learning arises from explanation and problem solving. Pierce wrote that it must be by abductive reasoning “... that we have the capacity to learn anything at all”.

Abductive reasoning gets its name from the way in which explanations are driven by (i.e., lead by) the data. It is reasoning from some given or observable effects to antecedent causes, and this marks the contrast with deductive reasoning. Unlike deduction which is a necessary and truth preserving form of inference (if you accept the premises of a deductive argument, you must accept the conclusion), abduction may only produce conclusions which are a current best guess: the explanations it generates (ie, the conclusions about antecedent causes) are the most likely explanation for the given event given the information currently available. Abductive inferences are probabilistic kind of reasoning, as are inductive inferences. However induction is essentially restricted to classifying the data or premises of arguments (e.g., tradititonally whether these or those swans are white), whereas abduction explains the causal relations between the facts. The form of abductive inference has been described by Josephson and Josephson (1996) as

$\mathrm{D}$ is a collection of data (facts, observations, givens),

$\mathrm{H}$ explains D (would, if true, explain D),

No other hypothesis explains $\mathrm{D}$ as well as $\mathrm{H}$ does.

Therefore, $\mathrm{H}$ is probably correct.

Our students can be seen to exhibit this form of reasoning about the verdict in the Vadera vs Shaw case. The first hypothesis advocated by the students corresponds with H3 in the domain analysis, the hypothesis that the general practitioner was careless but not professionally negligent. The single fact offered in relation to this explanation was the GP interpreting the unusually high blood pressure reading as anomalous. As additional facts are considered, this hypothesis becomes less sustainable as the best explanation, for example, the fact that the normal protocol would have been to take additional readings of blood pressure. A new hypothesis (H4), that the GP was negligent is considered, and is tentatively and rather tacitly agreed in Episode 4 of the dialogue. Up to this point the participants were distinguishing carelessness from negligence (some forms of carelessness will not be judged to be negligent, if they do not breach a duty of care and or there is no actual harm caused to a patient). The dialogue moves then (Episode 5) to consider the additional hypothesis (H5) about the 'not 
liable' part of the verdict. The first fact selected in relation to this hypothesis concerns the disputed consultation at which the GP is alleged to not have withdrawn the prescription. This fact properly relates to the GP's negligence and not their liability; the fact has not been included in the domain analysis because the fact is itself disputed in the case. Episode 6 continues the reasoning about the GP's liability and Gemma correctly identifies part of the explanation within this hypothesis, the question about what would have happened in the absence of the prescription. Hywel provides the additional fact about the statistical evidence to support Gemma's counterfactual explanation for hypothesis H5. He fails to recognize that the absence of a statistical relationship between the pill and strokes in general still allows the possibility that Ms Vadera was within a sub-population of hypertensives for whom there is a statistical relationship which would then imply the opposite hypothesis, H6, that the GP was liable. In her summing up in Episode 10, Gemma adopts Hywel's this flawed argument for fact F8 supporting hypothesis H5.

Walton 2005 emphasizes the discursive context of abductive reasoning in which explanation is driven by the need to find answers to successive questions. He says: "the structural correctness of an abductive inference depends on the transfer of understanding from one party to another in a dialogue. The best explanation is one that increases the understanding of a questioner as that individual moves forward through a search process. Of course, what increases understanding depends on the nature of the investigation...An abductive argument that is put forward by a proponent and meets the requirements for the scheme is to be evaluated in a given case with respect to how a respondent's critical questions are answered in a dialogue" (ibid p. 206). Walton is arguing that abductive reasoning needs to be regarded as a process as much as a conclusion and at a larger scale than individual inferences. The limited success of attempts to compare abductive, inductive and deductive reasoning are in part because of their focus on single inferences. As a process on a larger scale, Walton (2005) identifies four phases of abductive reasoning: dialogue setting, formation of explanation attempts, evaluation of explanations, and dialogue closure. These phases are evident in the students' dialogue. Explanations constructed are tested for their adequacy in explaining all the facts identified as relevant, and they are also assessed relative to the alternative explanations. The dialogue closure, which continues through Episodes 7 to 9, is lead by David who attempts a summing up of their argumentation around the distinct decision stages of the Bolam test. This summing up is unsuccessful either as reflecting the discussion that has been had, or indeed the elements of the verdict. The students agree on a conclusion based on the erroneous use of the statistical evidence.

\subsection{Learning}

The domain analysis (Figure 4) is a normative interpretation of the Vadera case (Figure 2) obtained by applying the essential concepts contained in the summary of the medical law of negligence (Figure 1). The original verdict in the case is explained by hypotheses $\mathrm{H} 1, \mathrm{H} 4$ and $\mathrm{H} 5$ in the domain analysis. The domain analysis can also be regarded as a statement of idealized learning outcomes for the Vadera case learning experience. If the students' concluded these three hypotheses, including the corresponding explanation and relevant facts, then it is reasonable to assume that they have also acquired the essential concepts of the law of medical negligence embodied in those hypotheses, and specifically, the conceptual distinction targeted between negligence (breaching a duty of care) from the concept of liability (responsibility for actual harm caused by a breach).

We can therefore identify statements in the dialogue which are evidence of the use of acquired concepts. Figure 5 summarises the analysis of the semantic core of the dialogue by comparing the student argumentation against the domain analysis. The table summarises 
which elements of the domain analysis were identified in the student argumentation. For example, the argumentation explicitly refers to Hypothesis H1 but neither the explanation for that hypothesis (E1) nor the relevant fact (F1) were explicitly stated (David correctly states in Episode 8 that there was no doubt about the hypothesis that the GP had a duty of care). This summarization makes clear the incompleteness of the students' argumentation Two hypotheses are not discussed at all, the facts associated with each hypothesis are only partially identified and only one explanation for a hypothesis is explicitly contributed.

The students definitively conclude on $\mathrm{H} 5$, although they identify just one fact as relevant to this hypothesis and they only identify part of the explanation connecting the relevant facts to this hypothesis. In Episode 8, where the students sum up their collective conclusions, the issue of whether a duty of care was breached is again confounded (this time by Hywel) with the issue of whether the alleged breach caused the stroke. This confusion is left uncorrected and as a result it is ambiguous whether the students are adopting hypothesis H4 (the GP was negligent) or adopting a new hypothesis H2 (the GP was without fault). The failure to resolve the confusion can be interpreted as a weak dissociation of the concepts of negligence and liability.

In individual reports written immediately following the learning experience, each of the students does indicate a grasp of the distinction between negligence and liability. The responses, shown in Figure 6, indicate a separate consideration of the acceptability of the GP's actions and the causation for the harm suffered by the patient.

These post-session responses need to be interpreted against responses given before the start of the learning session when the students were asked to write a short account of their knowledge of the law relating to medical negligence. At that point only David explicitly distinguished the issue of assessing a GP's professional behaviour separately from the issue of responsibility for harm suffered by a patient which might have been caused by that behaviour. Gemma and Hywel acquire this dissociation through exposure to the Vadera/Shaw verdict, as consideration of the set of facts is broadened and as one hypothesis is abandoned in favour of another which more successfully accounts for the facts.

The students then have grasped the abstract distinction between negligence and liability but their operationalisation of it within the Vadera case is relatively weak. Note in Episode 5 the way in which David implies that the key issue in deciding the GP's liability was whether she had ignored contra-indications to the prescription at a follow-on consultation. By implication, David falsely believes that a GP could not be liable simply for making a prescription to a patient. Gemma then moves the discussion on to establish the counter-factual argument which will decide the matter. David acknowledges immediately the correctness of Gemma's argument as the central issue in deciding the GP's liability and abandons his own flawed argument. David is learning to operationalise his concept of liability through the interaction.

This acquisition of new knowledge about medical negligence appears to be shaped by the abductive argumentation scheme. A tentative hypothesis is abandoned as new facts are considered, and a new hypothesis is tentatively accepted. As one hypothesis succeeds another, the conceptual differences underlying those hypotheses are exposed and produce a dissociation which we recognize as learning.

\section{4: Review}

Our aim was to identify the cognitive mechanism through which learning arises from argumentation in collaborative case-based learning. This aim follows from Jermann and Dillenbourg's description of the primary scientific issue facing research in argumentation and 
learning technologies. We wanted to identify the argumentation scheme which characterizes the reasoning which is intrinsic to collaborative case-based learning. Argumentation schemes are stereotypical domain-specific forms of reasoning. We collected a dialogue from three medical students learning about medical law with a case of medical negligence. This case material differs markedly from the structured and closed problems (e.g, applied mechanics problems involving static bodies) often used in collaborative problem-based learning research and we believe it is more representative of the kinds of domain (complex, partially structured, open) for which case-based collaborative learning is suited. The students were working within a distributed virtual learning environment developed for the purpose with materials developed to enable scrutiny of the particular conceptual distinction between negligence and liability. We found that the students' dialogue conformed had features of both persuasion and inquiry dialogues. The argumentation scheme evident in the dialogue was of the abductive type, sometimes referred to as 'inference to the best explanation'. The effectiveness of the learning experience was mixed. The students grasped the distinction between negligence and liability but their operationalisation of it, that is, their ability to interpret the concepts for the particular facts of the Vadera case, is weak. Nevertheless, the acquisition of the central conceptual distinction appears to arise through the abductive process of exploring successive explanations to fit a broadening consideration of the case facts.

Our focus on the essential relationship between argumentation and learning in collaborative case-based learning has necessarily led us to make several assumptions and exclude some interesting related questions. We have, for example, not examined here the effect on argumentation of the computer mediated communication which our students experienced. We believe that identifying the argumentation scheme of case based learning is a needed prior task for the research and once achieved can make the investigation of the technology and process factors more focused and rapid. We have also treated argumentation as the collective reasoning of the group and avoided the dispute over fundamentals concerning how collaboration contributes to learning more generally. Collaborative learning has been described as essentially a process of convergence in which the participants develop a shared solution by integrating their different understandings of underlying concepts (Roschelle, 1992). Yet it has also been described as a process where each participant separately revises their understanding of underlying concepts using the exchanges with others as stepping stones, even while the solution to the problem is being expressed collectively and with collective agreement (Shirouzu and Miyake, 2002). Our approach allows progress on investigating collaborative case based learning without committing to either position and may in fact help reframe those positions enabling more rapid progress on the questions of the relationships between argumentation, learning and learning technologies.

We acknowledge the support of the Economic and Social Research Council, award no. L328 253013

\section{References}

Baker M. (2003) Computer-mediated argumentative interactions for the co-elaboration of scientific notions. In Andriessen J., Baker M. and Suthers D. (ed.s) Arguing to learn. Kluwer Academic: Netherlands.

Jermann P. \& Dillenbourg P. (2003) Elaborating new arguments through a CSCL script. In Andriessen J., Baker M. and Suthers D. (ed.s) Arguing to learn. Kluwer Academic: Netherlands.

Goldberg, R. (2000) The Contraceptive Pill, Negligence and Causation: Views on Vadera v. Shaw, The Medical Law Review, volume 8, pages 316-338

Honderich, T. (ed.) (1995). The Oxford Companion to Philosophy, Oxford University Press. 
Josephson, J. R. \& Josephson, S. G. (1996) Abductive Inference, Computation, Philosophy, Technology, Cambridge University Press.

Koschmann T. (2003) CSCL, argumentation and deweyan inquiry. In Andriessen J., Baker M. and Suthers D. (ed.s) Arguing to learn. Kluwer Academic: Netherlands.

Magnani, L. (1992) Abductive Reasoning: Philosophical and Educational Perspective on Medicine. In D. A. Evan, \& V. L. Patel (Eds.), Advanced Models of Cognition in Medical Training and Practice, Berlin, Springer.

Peirce, C. S. (1997) Pragmatism as a Principle and Method of Right Thinking. In Patricia Ann Turrisi (Ed.), The 1903 Harvard Lectures on Pragmatism, State University of New York Press, Albany.

Roschelle, J. (1992) Learning by collaborating: Convergent conceptual change. The Journal of the Learning Sciences, v2(3), 235-276.

Shirouzu H. and Miyake N. (2002) Learning by collaborating revisted: individualistic vs convergent understanding. Proceedings of the 24th Annual Conference of the Cognitive Science Society, USA, 1039.

Sirocchi F., (2003) Integration of an interaction tool for synchronous collaboration into a web based learning management system. In Proceedings of IPSI 2003, International Conference on Advances in the Internet, Sveti Stefan, Montenegro, 4 October 2003.

Simon, H. A. (1965) The Logic of Rational Decision, British Journal for the Philosophy of Science, v16, 169186.

Simon, H. A. (1977) Models of Discovery and Other Topics in the Methods of Science. Dordrecht, Reidel.

Suthers D.D. \& Hundhausen C.D. (2003) An Experimental Study of the Effects of Representational Guidance on Collaborative Learning Processes, Journal of the Learning Sciences, 2003, Vol. 12, No. 2, Pages 183-21

Walton D. (1989) Informal logic: a handbook for critical argumentation. Cambridge University Press.

Walton D. (2005) Abductive Reasoning. Alabama University Press. 
Figure 1 Summary of the law of medical negligence given to the students before the case discussions. The summary contains the main points from a lecture the students had previously attended.

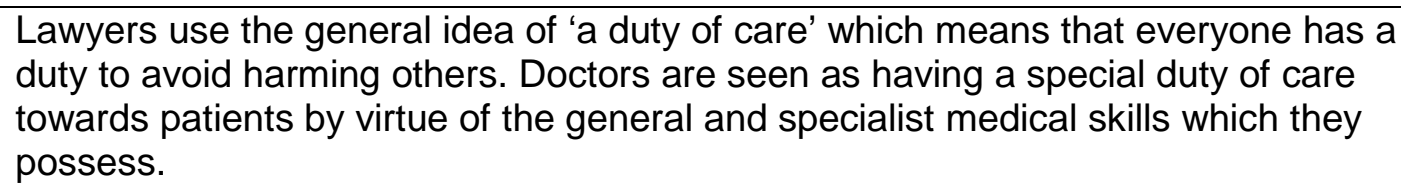

If a doctor behaves in a way which is not professionally responsible, then he may fail to maintain the duty of care he has for a patient, and he may then be judged to be negligent. Being negligent may involve following some form of action, or failing to follow some form of action.

Lawyers make a distinction between negligence and liability: you may be judged to be negligent but not liable for what happened to a patient. To be liable for the consequences of their negligent actions, it would have to be shown that if the doctor had not acted in a certain way then the harm would not have taken place. However, if the doctor couldn't have been expected to see the outcome because it was too unlikely or too remote from the situation he was in, then even if harm resulted, he wouldn't be held responsible.

So how can we assess (i) whether the professional behaviour of the doctor was irresponsible, (ii) whether the damage which resulted from this irresponsible behaviour was really down to him/her? This is decided by a body of experts who must establish what would be the expected standard of practice in the given situation and whether that standard was met by the actions of the doctor.

Figure 2. Description of the Vadera vs Shaw case.

\begin{abstract}
A 22-year old asian woman presented herself 3 times within a year at her GP's practice, with the intention of starting contraception before her marriage. She was to be married on $30^{\text {th }}$ of November and was eager to start the contraception. She was warned that there were health risks associated with contraceptive pills. On the third visit, on $11^{\text {th }}$ of October, her blood pressure was taken and it was at 150/100 (higher than normal for a woman of her age). This high reading was taken by the GP (Dr. Shaw) as a symptom of 'white-coat hypertension', a phenomenon caused by anxiety of being a doctor's presence that can however also be indicative of a general tendency to hypertension. The next day, she started the pill. She claims that within 3 weeks she returned to the GP complaining about headaches and feeling generally ill. She says the GP prescribed a medication for the headache. The GP claims this meeting did not take place and records of any meetings that occurred during this period were no longer available. A week later, the plaintiff was admitted to hospital suffering from numbness and difficulty in walking. Her blood pressure was read several times and was variously found to be at 170/110, 110/60 and 140/110. She was diagnosed as having suffered a stroke.
\end{abstract}

Note: the statistical evidence does not link taking contraceptives with stroke, over the population as a whole.

Verdict: in the first instance the judge found the GP to be negligent but not liable. 


\section{Learning by arguing about evidence and explanations}

Figure 3: the dialogue

\begin{tabular}{|c|c|c|}
\hline $\begin{array}{l}\text { timestamp } \\
\text { (hr:min:sec) } \\
\text { Student }\end{array}$ & & $\mathrm{DA}$ \\
\hline \multicolumn{3}{|l|}{ EPISODE1 } \\
\hline $\begin{array}{l}\text { 14:22:24 } \\
\text { David }\end{array}$ & $\begin{array}{l}\text { So our task is to justify the } \\
\text { verdict? }\end{array}$ & \\
\hline $\begin{array}{l}\text { 14:22:36 } \\
\text { Hywel }\end{array}$ & yes. let's do it! & \\
\hline $\begin{array}{l}\text { 14:22:38 } \\
\text { Gemma }\end{array}$ & Ok & \\
\hline $\begin{array}{l}\text { 14:23:07 } \\
\text { David }\end{array}$ & $\begin{array}{l}\text { The fact is im not sure taht } i \\
\text { actually agree with it }\end{array}$ & \\
\hline $\begin{array}{l}\text { 14:23:07 } \\
\text { Gemma }\end{array}$ & $\begin{array}{l}\text { first, does anyone completely } \\
\text { disagree with the verdict?" }\end{array}$ & \\
\hline $\begin{array}{l}\text { 14:23:12 } \\
\text { David }\end{array}$ & *. & \\
\hline $\begin{array}{l}\text { 14:23:15 } \\
\text { Gemma }\end{array}$ & ok... & \\
\hline \multicolumn{3}{|l|}{ EPISODE2 } \\
\hline $\begin{array}{l}\text { 14:23:40 } \\
\text { Gemma }\end{array}$ & What do u think about it david? & \\
\hline $\begin{array}{l}\text { 14:23:45 } \\
\text { David }\end{array}$ & $\begin{array}{l}\text { maybe the GP was a bit naive with } \\
\text { teh white coat business }\end{array}$ & $\mathrm{H} 3$ \\
\hline $\begin{array}{l}\text { 14:23:56 } \\
\text { David }\end{array}$ & i mean 150/100? & $\mathrm{F} 3$ \\
\hline $\begin{array}{l}\text { 14:24:05 } \\
\text { Gemma }\end{array}$ & so u would think that she is liable? & $\mathrm{H} 4$ \\
\hline $\begin{array}{l}\text { 14:24:28 } \\
\text { David }\end{array}$ & i would tend to say no & \\
\hline $\begin{array}{l}\text { 14:24:39 } \\
\text { David }\end{array}$ & but I am evidently wrong here & \\
\hline $\begin{array}{l}\text { 14:24:55 } \\
\text { Gemma }\end{array}$ & i don't think I'm understanding $u$ ? & \\
\hline $\begin{array}{l}\text { 14:25:14 } \\
\text { Gemma }\end{array}$ & $\begin{array}{l}\text { which part of the verdict would } u \\
\text { tend to disagree with? }\end{array}$ & \\
\hline $\begin{array}{l}\text { 14:25:35 } \\
\text { David }\end{array}$ & $\begin{array}{l}\text { well, i think the GP was maybe a } \\
\text { little naive to say that such a high } \\
\text { BP was white coat hypertension }\end{array}$ & $\begin{array}{l}\mathrm{H} 3 \\
\mathrm{~F} 3\end{array}$ \\
\hline $\begin{array}{l}\{14: 25: 55\} \\
\text { Gemma }\end{array}$ & $\begin{array}{l}\text { Yep i think i could agree with } u \\
\text { there... }\end{array}$ & \\
\hline $\begin{array}{l}\text { 14:25:46 } \\
\text { David }\end{array}$ & but $i$ think it was a fair diagnosis & $\mathrm{H} 3$ \\
\hline $\begin{array}{l}\text { 14:26:11 } \\
\text { Gemma }\end{array}$ & $\begin{array}{l}\text { so u think she was right in } \\
\text { prescribing the pill anyway? }\end{array}$ & F5 \\
\hline \multicolumn{3}{|l|}{ EPISODE3 } \\
\hline $\begin{array}{l}14: 26: 18 \\
\text { Hywel }\end{array}$ & $\begin{array}{l}\text { shouldn't he have repeated the } \\
\text { test again at another time }\end{array}$ & $\mathrm{F} 4$ \\
\hline $14: 26: 21$ & Potentially & \\
\hline
\end{tabular}

\begin{tabular}{|c|c|c|}
\hline David & & \\
\hline $\begin{array}{l}\text { 14:26:28 } \\
\text { Gemma }\end{array}$ & Yeh thats what $\mathrm{i}$ though & \\
\hline EPISODE4 & & \\
\hline $\begin{array}{l}14: 26: 37 \\
\text { David }\end{array}$ & $\begin{array}{l}\text { maybe she would have been better } \\
\text { off taking repeated BP's, maybe at } \\
\text { home? }\end{array}$ & $\mathrm{F} 4$ \\
\hline $\begin{array}{l}\{14: 26: 51\} \\
\text { David }\end{array}$ & $\begin{array}{l}\text { somewhere where the element of } \\
\text { the doctors presence was reduced }\end{array}$ & $\mathrm{F} 4$ \\
\hline $\begin{array}{l}\text { 14:26:41 } \\
\text { Hywel }\end{array}$ & $\begin{array}{l}\text { so he was negligent- he behaved } \\
\text { irresponsibly }\end{array}$ & $\mathrm{H} 4$ \\
\hline $\begin{array}{l}\text { 14:26:59 } \\
\text { David }\end{array}$ & Or did he? & \\
\hline $\begin{array}{l}\{14: 26: 40\} \\
\text { Gemma }\end{array}$ & $\begin{array}{l}\text { And we don't know what kind of } \\
\text { history the GP took }\end{array}$ & $\mathrm{F} 4$ \\
\hline $\begin{array}{l}\text { 14:27:08 } \\
\text { David }\end{array}$ & True & \\
\hline $\begin{array}{l}\text { 14:27:12 } \\
\text { Hywel }\end{array}$ & i agree & \\
\hline EPISODE5 & & \\
\hline $\begin{array}{l}\text { 14:27:35 } \\
\text { Hywel }\end{array}$ & what about the not libale part? & $\mathrm{H} 5$ \\
\hline $\begin{array}{l}\text { 14:27:42 } \\
\text { David }\end{array}$ & $\begin{array}{l}\text { I think that the crux here is } \\
\text { whether the second meeting took } \\
\text { place }\end{array}$ & \\
\hline $\begin{array}{l}\text { 14:28:01 } \\
\text { Gemma }\end{array}$ & Yeh & \\
\hline $\begin{array}{l}\{14: 28: 11\} \\
\text { David }\end{array}$ & $\begin{array}{l}\text { if it did, and the GP fobbed her } \\
\text { off, then definate case for } \\
\text { negligance, not having followed up } \\
\text { the symptoms etc. }\end{array}$ & \\
\hline $\begin{array}{l}\{14: 28: 36\} \\
\text { David }\end{array}$ & $\begin{array}{l}\text { but, if not then the GP wasnt to } \\
\text { know about any adverse affects } \\
\text { experienced }\end{array}$ & \\
\hline $\begin{array}{l}\text { 14:28:08 } \\
\text { Hywel }\end{array}$ & $\begin{array}{l}\text { what responsibility does the doctor } \\
\text { have for keeping the records safe? }\end{array}$ & \\
\hline $\begin{array}{l}\text { 14:28:30 } \\
\text { Gemma }\end{array}$ & $\begin{array}{l}\text { yeh what about at the pharmacy, } \\
\text { wouldn't there be a record of the } \\
\text { prescription there? }\end{array}$ & \\
\hline EPISODE6 & & \\
\hline $\begin{array}{l}\text { 14:29:26 } \\
\text { Gemma }\end{array}$ & $\begin{array}{l}\text { really the question is, would she } \\
\text { have suffered the stroke if she } \\
\text { hadn't been on the pill? }\end{array}$ & H5 E5 \\
\hline $\begin{array}{l}\{14: 29: 33\} \\
\text { David }\end{array}$ & Indeed & \\
\hline $\begin{array}{l}\{14: 29: 41\} \\
\text { Hywel }\end{array}$ & apparently not- statistically anyway & F8 \\
\hline
\end{tabular}


Learning by arguing about evidence and explanations

\begin{tabular}{|c|c|c|}
\hline EPISODE7 & & \\
\hline $\begin{array}{l}\text { 14:29:28 } \\
\text { David }\end{array}$ & so on Bolam negligance ${ }^{1}$ & \\
\hline $\begin{array}{l}\text { 14:29:40 } \\
\text { David }\end{array}$ & there was abviously a duty of care & $\mathrm{H} 1$ \\
\hline $\begin{array}{l}\text { 14:30:02 } \\
\text { Hywel }\end{array}$ & what's bolam negligence? & \\
\hline $\begin{array}{l}\text { 14:30:14 } \\
\text { David }\end{array}$ & The three poibnt negligance test & \\
\hline $\begin{array}{l}\{14: 30: 28\} \\
\text { David }\end{array}$ & $\begin{array}{l}\text { duty of care, breach of duty, and } \\
\text { harm caused by breach }\end{array}$ & \\
\hline $\begin{array}{l}\text { 14:30:26 } \\
\text { Gemma }\end{array}$ & $\begin{array}{l}\text { basically if u have a room full of } \\
\text { doctors and the majority agrees } \\
\text { with what u did then u r ok:) }\end{array}$ & \\
\hline $\begin{array}{l}\text { 14:30:38 } \\
\text { David }\end{array}$ & Well sadi! & \\
\hline $\begin{array}{l}\text { 14:30:42 } \\
\text { David }\end{array}$ & Said* & \\
\hline \multicolumn{3}{|l|}{ EPISODE8 } \\
\hline $\begin{array}{l}\text { 14:31:21 } \\
\text { David }\end{array}$ & $\begin{array}{l}\text { so are we suggesting that the GP } \\
\text { was not guilty of breach of duty? }\end{array}$ & $\mathrm{H} 2 / 3$ \\
\hline $\begin{array}{l}\text { 14:31:24 } \\
\text { Hywel }\end{array}$ & $\begin{array}{l}\text { so if he took the same action as } \\
\text { any other doctor would have (which } \\
\text { the facts show that he did) he is } \\
\text { not liable }\end{array}$ & $\begin{array}{l}\mathrm{H} 5 \\
\mathrm{~F} 6\end{array}$ \\
\hline \multicolumn{3}{|l|}{ EPISODE9 } \\
\hline $\begin{array}{l}\text { 14:31:40 } \\
\text { Gemma }\end{array}$ & $\begin{array}{l}\text { i say that because of the lack of } \\
\text { statistical evidence linking the pill } \\
\text { with stroke that the verdict is } \\
\text { justified }\end{array}$ & $\begin{array}{l}\mathrm{H} 5 \\
\mathrm{~F} 8\end{array}$ \\
\hline $\begin{array}{l}\text { 14:31:40 } \\
\text { David }\end{array}$ & Agreed & \\
\hline $\begin{array}{l}\text { 14:31:48 } \\
\text { Hywel }\end{array}$ & Agreed & \\
\hline
\end{tabular}

Bolam negligence is the principle that a panel of experts should decide whether a doctor's actions have fallen below the expected standard. 
Figure 4. Domain analysis (DA) of the Vadera vs Shaw case

\section{Hypothesis H1. The GP had a duty of care to Vadera}

Explanation: Because GPs have a duty of care to their registered patients

Relevant facts: F1.

Hypothesis H2 The GP did not breach her duty of care to the patient.

Explanation: Because it was reasonable for the GP to assume that the bp reading was anomalous for such a young patient. Any other GP of 'the same skill' would have made the same judgement.

Relevant facts: F2; F3.

Hypothesis H3 The GP was careless but did not breach her duty of care to the patient

Explanation: Because the GP should have checked the reliability of the bp reading

Relevant facts: F2; F3; F4

Hypothesis H4. The GP breached her duty of care to the patient:

Explanation: Because the GP prescribed the pill to Ms Vadera who was most likely suffering from hypertension.

Relevant facts: F3; F4; F5; F6; F7

\section{Hypothesis H5. The GP was not liable for Vadera's stroke}

Explanation: Because the patient was likely to have been hypertensive and her hypertension was the cause of her stroke. Her original bp reading and those taken in the hospital are evidence of hypertension. She would not have suffered a stroke if she had not been hypertensive. The prescription may have had a contributory effect, but it is possible and even probable that Vadera would have suffered a stroke without the prescription.

Relevant facts: F8; F9

\section{Hypothesis H6. The GP was liable for Vadera's stroke}

Explanation: The statistical evidence covers the population in general but for hypertensive women there may be an effect of the pill on the prevalence of strokes. Ms Vadera was hypertensive, as indicated by the bp readings recorded for her before and after the stroke. The prescription of the pill had a significant role in causing the stroke. The GP's negligence in not identifying Ms Vadera's hypertension led to the actual harm she suffered.

Relevant facts: F8; F9 
F1. Vadera was a registered patient with the GP

F2. The patient was young

F3. bp readings can sometimes be anomalous due to 'white coat syndrome' (anxiety in the presence of a doctor)

F4 The GP did not confirm the bp readings.

F5 The GP prescribed the pill without confirming the bp reading.

F6 The GP did not follow the protocol for screening patients before prescribing the pill

F7 The GP did not investigate further whether the patient had hypertension which needed to be treated.

F8. Statistics show, over the population at large, no effect of the pill on the likelihood of suffering a stroke.

F9. The very high bp readings taken at the hospital indicate that Ms Vadera was hypertensive.

Figure 5. Assessment of learning outcomes

\begin{tabular}{|l|l|}
\hline $\begin{array}{l}\text { Domain analysis (normative) of the } \\
\text { Vadera-Shaw case }\end{array}$ & $\begin{array}{l}\text { Explicitly present in } \\
\text { student argumentation }\end{array}$ \\
\hline H1. & $\mathrm{H} 1$ \\
E1. & \\
F1 & \\
H2 & \\
E2 & \\
F2; F3. & \\
\hline H3 & H3 \\
E3 & \\
F2; F3; F4 & F3 \\
\hline H4 & H4 \\
E3 & \\
F3; F4; F5; F6; F7 & F4 F5 \\
\hline H5. & H5 \\
E5 & E5 \\
F8; F9 & F6 F8 \\
\hline H6. & \\
E6 & \\
F8; F9 & \\
\hline
\end{tabular}


Figure 6. Following the learning session, individual written responses to the question 'what were the main issues in the scenario?'

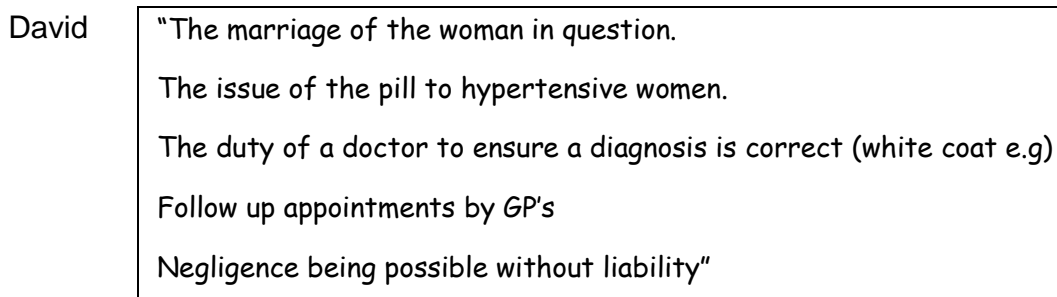

Hywel "Whether it was appropriate to attribute the hypertention to white coat syndrome

The problem that the patients' medical notes are missing

As the statistical evidence finds no connection between taking the pill and suffering a stroke it is not possibl attribute the doctor's actions to the patient suffering a stroke" 